\title{
EL CONCEPTO DE DERECHOS HUMANOS FRENTE A LOS DERECHOS DE LAS MINORÍAS ÉTNICAS*
}

\author{
Samir Hendrix Guerrero Pino** \\ Lisneider Hinestroza Cuesta **
}

Fecha de recepción: 11 de agosto de 2016

Fecha de evaluación: 20 de febrero de 2017

Fecha de aprobación: 16 de mayo de 2017

Artículo de investigación

DOI: http://dx.doi.org/10.18359/prole.3039

Forma de citación: Guerrero, S. H. \& Hinestroza, L. (2017). El concepto de derechos humanos frente a los derechos de las minorías étnicas. Revista Prolegómenos Derechos y Valores, 20, 40, 27-41. DOI: http://dx.doi. org/10.18359/prole.3039

\section{Resumen}

Los derechos humanos han evolucionado hasta el punto de reconocer derechos de naturaleza colectiva como los derechos de las minorías étnicas. Este artículo explica cómo pueden categorizarse los derechos de las minorías étnicas como derechos humanos. La investigación es de corte analítico-conceptual, utiliza el método de investigación deductivo y los de interpretación jurídica: histórico, sistemático, sociológico y teleológico o finalista, para concluir con la identificación de algunos criterios que pueden servir de base para incluir derechos colectivos como los de las minorías étnicas, en el discurso contemporáneo de los derechos humanos.

\section{Palabras clave:}

Derechos humanos, minorías étnicas, derechos de tercera generación.

- Artículo producto del proyecto de investigación: "Estudio jurídico sobre el derecho humano a la propiedad colectiva de las comunidades negras en Colombia", adscrito al Grupo de Investigación Derecho, Sociedad y Medio Ambiente, línea grupos étnicos y medioambiente de la Facultad de Derecho de la Universidad Tecnológica del Chocó "Diego Luis Córdoba" (Quibdó, Colombia), financiado por el Departamento Administrativo de Ciencia, Tecnología e Innovación (Colciencias) por medio del Programa Jóvenes Investigadores, modalidad tradicional; Convocatoria para la Formación de Capital Humano de Alto Nivel para el Departamento del Chocó $\mathrm{N}^{\circ} 694$.

* Abogado, joven investigador por medio del proyecto avalado por Colciencias (2015-2016) denominado: "Estudio jurídico sobre el derecho humano a la propiedad colectiva de las comunidades negras en Colombia".

Correo electrónico: e-samir.guerrero@utch.edu.co

** Abogada, magíster en Derecho de los Recursos Naturales de la Universidad Externado de Colombia (Bogotá, Colombia), estudiante de tercer año de doctorado en Derecho de la misma universidad. Líder del Grupo de Investigación Derecho, Sociedad y Medio Ambiente de la Facultad de Derecho de la Universidad Tecnológica del Chocó "Diego Luis Córdoba" (Quibdó, Colombia). Docente asistente en Comisión de Estudios de la Universidad Tecnológica del Chocó "Diego Luis Córdoba", Vicerrectoría de Investigaciones - Centro de Investigaciones en Biodiversidad y Hábitat. Correo electrónico: d-lisneider.hinestroza@utch.edu.co 


\title{
CONCEPT OF HUMAN RIGHTS OPPOSITE TO THE RIGHTS OF ETHNIC MINORITIES
}

\begin{abstract}
Summary
Human Rights have evolved to the point of recognizing collective nature rights as well as ethnic minority rights (article 27, International Covenant on Civil and Political Rights, adopted by the General Assemble of the United Nations on December 16th, 1966). This article explains how the ethnic minority rights can be categorized as human rights. This research is analytical-conceptual based, it uses the deductive method and those of legal interpretation such as historic, systematic, sociologic and either teleological or finalist, and concludes by identifying some criteria, which might be used as a cornerstone to include collective rights - as those of the ethnic minorities - in the same contemporary discourse of human rights.
\end{abstract}

\section{Keywords:}

Human rights, ethnic minorities, third generation rights.

\section{O CONCEITO DE DIREITOS HUMANOS FRENTE AOS DIREITOS DAS MINORIAS ÉTNICAS}

\begin{abstract}
Resumo
Os direitos humanos têm evoluído ao ponto de reconhecer direitos de natureza coletiva como os direitos das minorias étnicas (artigo 27 do Pacto Internacional de Direitos Civis e Políticos, de 16 de dezembro de 1966, adoptado pela Assembleia Geral das Nações Unidas). Este artigo explica como podem ser categorizados os direitos das minorias étnicas como direitos humanos. A pesquisa é de caráter analítico-conceitual, utiliza o método de investigação dedutivo e os de interpretação jurídica: histórico, sistemático, sociológico e teleológico ou finalista, para concluir com a identificação de alguns critérios que podem servir de base para incluir os direitos coletivos, como os das minorias étnicas, no discurso contemporâneo dos direitos humanos.
\end{abstract}

\section{Palavras-chave:}

Direitos humanos, minorias étnicas, direitos de terceira geração.

Si en lugar de negar la identidad del otro, la reconocemos, incluso como presente dentro de nosotros, nuestra cosmovisión se expande. El mundo no se nos derrumba si nos abrimos a la identidad-en-la-diferencia, sino que se enriquece con nuevos contenidos.

Ernesto Ottone

\section{Introducción}

El 10 de diciembre de 1948 la Asamblea General de las Naciones Unidas institucionalizó el concepto universal de los derechos humanos. No obstante, dicho concepto desconoció la realidad cultural de las minorías étnicas, razón por la cual, el 16 de diciembre de 1966 a través del artículo 27 del Pacto Internacional de Derechos Civiles y Políticos se incluyeron los derechos de las minorías étnicas en la noción universal de los derechos humanos. Sin embargo, aún existen teorías que niegan la conceptualización de los derechos de las minorías étnicas como derechos humanos (teoría de la universalidad), que manifiestan que son compatibles pero dife- 
rentes (teoría de la especificación) o que niegan el concepto universal de los derechos humanos (teoría del relativismo cultural).

Por lo anterior, este trabajo realiza análisis de las distintas concepciones sobre los derechos humanos y parte de los elementos esenciales para su interpretación; además presenta los criterios que hoy en día permiten categorizar los derechos de las minorías étnicas como derechos humanos.

Este artículo explica el concepto de derechos humanos a partir de las principales visiones o concepciones del derecho: cristiana o teológica, iusnaturalista racional, iuspositivista y contemporánea. El propósito es observar los enfoques de las principales teorías jurídicas sobre los derechos humanos e identificar cuáles están vigentes, de este modo, entender qué contribuye a que determinados derechos, particularmente los de las minorías étnicas, se conceptualicen como derechos humanos por el derecho internacional contemporáneo.

Luego expone el concepto de minorías puntualizando en las de naturaleza étnica, con especial interés en las minorías étnicas colombianas. También se describe cómo surgieron los derechos de las minorías étnicas en el derecho internacional, para después especificar dentro de las categorías de derechos humanos el corpus iuris ${ }^{1}$ de los derechos de las minorías étnicas.

\footnotetext{
El término corpus juris es utilizado por la Corte Interamericana de Derechos Humanos (opinión consultiva OC-16/1999) para aludir de manera sistemática a las normas internacionales tipo declaración, convenio, pacto o resoluciones que contienen los derechos humanos. En el presente documento, se referencia el mismo término y sistemáticamente, pero para identificar las normas sobre los derechos de las minorías étnicas, que conceptualizan sus derechos como derechos humanos por el derecho internacional.
}

Por último, manifiesta con fundamentos normativo-conceptuales empleando sobre todo los métodos de interpretación jurídica: histórico (Monroy, 2013), sistemático (López, 2006; Naranjo, 2006), sociológico y teológico o finalista (De Asís, 2005), cómo pueden categorizarse los derechos de las minorías étnicas como derechos humanos.

\section{A. El concepto de derechos humanos ${ }^{2}$}

En este aparte se estudia el concepto de derechos humanos desde la concepción del derecho teológico, iusnaturalista racional, iuspositivista y contemporáneo siguiendo dos criterios: normativo y doctrinario.

Esto por cuanto los derechos humanos intitulados (siguiendo un criterio eminentemente normativista) así por el ordenamiento jurídico internacional universal (Declaración Universal de los Derechos Humanos de 1948, los pactos internacionales de $1966^{3}$ y las demás normas complementarias), internacional continental (verbi gratia, en el continente americano la Convención Americana sobre Derechos Humanos de 1969) e interno (por ejemplo, el artículo 93 inciso 1 de la Constitución Política de Colombia de 1991 que enuncia el reconocimiento de los derechos humanos por medio de tratados y convenios internacionales), no son el resultado de un proceso político reciente como lo explica el exjuez y expresidente de la Corte Interamericana de Derechos Humanos Pedro Nikken (1994).

Este artículo no estudia el contenido de las concepciones del derecho referenciadas en sensu lato, por el contrario, se limita a identificar algunas de sus precisiones o conceptos vigentes en la definición contemporánea de derechos humanos, de este modo, entender que contribuye a que determinado derecho, particularmente los de las minorías étnicas, sea categorizado como derecho humano por el derecho internacional vigente.

3 Los pactos internacionales de 1966 son el Pacto Internacional de Derechos Económicos, Sociales y Culturales y el Pacto Internacional de Derechos Civiles y Políticos, ambos adoptados por la Asamblea General de las Naciones Unidas el 16 de diciembre de 1966. 
En orden cronológico, en primer lugar, está el aporte de la concepción teológica del derecho. Esta visión afirma que los derechos son creados por Dios y que el hombre los descubre por medio de la ratio (razón), resumiendo las particularidades que referencia Werner Goldschmidt (citado en Monroy, 2015). Respecto de esta línea de pensamiento dice Augusto González Ramírez (2015) que

[...] el origen del derecho para esta posición teológica-tradicional debe remontarse hasta el autor de la naturaleza (Dios), a la cual gobierna (divina providencia) y ha impuesto su voluntad un orden general, que puede ser conocido en parte por el hombre, ya sea por intermedio de la revelación y la tradición, o mediante el intelecto humano, lo que constituye precisamente el derecho natural [...] (p. 34).

Por medio de la fundamentación divina los próceres del "jusnaturalismo teológico" (Giraldo, Giraldo y Giraldo, 2002) atribuyen unas características a los derechos del hombre y algunas (aunque revaluadas, claro está) de ellas hoy por hoy están vigentes en el concepto jurídico de derechos humanos.

En este sentido, el exmagistrado de la Corte Constitucional colombiana Vladimiro Naranjo Mesa (2006) sintetiza algunas contribuciones de la "fundamentación teológica del derecho" (Atienza, 2011, p. 48) diciendo que "ideas como la de la soberanía popular, el contrato social, la superioridad del derecho natural sobre el derecho positivo, la sujeción del gobernante a la ley o el derecho de resistencia a la ley injusta [...]" (Naranjo, 2006, p. 38) son desarrollo de la teoría en mención.

En pocas palabras, para la concepción cristiana los derechos se descubren mediante la razón, en la naturaleza, la cual es creada por Dios (González, 2015), por consiguiente, las teorías de esta ideología basan sus argumentos en este tipo de "poder" o "fuerza" inmaterial. Tal criterio, para el concepto actual de derechos humanos es insuficiente sobre todo porque la autoridad que interpreta o descubre los derechos según esta posición es la Iglesia (González, 2015).

En sentido contrario, en el iusnaturalismo posteológico se sostiene que los derechos son creados por la naturaleza y que el hombre los descubre a través de la razón (Giraldo et al., 2002), pero independiente de intervención divina alguna. Esta concepción es denominada como "jusnaturalismo racional" (Giraldo et al., 2002) o "escuela del derecho racional" (Monroy, 2015) según referencias de los autores en cita.

Marco Gerardo Monroy Cabra (2015) sostiene que "según esta escuela, la razón es no solo el instrumento por el que conocemos el derecho natural, sino también la base o fundamento de su existencia" (p. 16). El jurista holandés Hugo Grocio (citado en Bidart, 1989, p. 101) manifestó que "el derecho natural existiría aunque Dios no existiera" o en palabras de González Ramírez (2015), "en la Edad Moderna se consideró que la esencia y fundamento del derecho natural se hallaba en la 'naturaleza humana' ajena a toda injerencia religiosa" (p. 34).

Las contribuciones de la "escuela del derecho racional" (Monroy, 2015) al concepto de derechos humanos a partir de la razón como su única fuente, pueden deducirse de las precisiones de Naranjo Mesa (2006), el tratadista español Gregorio Peces-Barba Martínez (1994) y los profesores Carlos Fuentes López (2003) y Augusto González Ramírez (2015).

Naranjo Mesa (2006) asegura que para la corriente del derecho natural los derechos de los hombres son universales, permanentes e inalienables, que son anteriores "a la formación del Estado" y que "sus principios no necesitan ser consagrados expresamente por el gobernante; se imponen a él y están vigentes para todos los seres y pueblos del mundo, cualquiera sea su nivel de desarrollo o civilización" (Naranjo, 2006, p. 9).

Peces-Barba Martínez (1999, p. 42) explica que "se trata de derechos del hombre en el estado 
de naturaleza y, consiguientemente, previos al Estado y al derecho positivo", que "son producto de la razón, descubribles en la naturaleza humana, tienen un carácter abstracto, afectan al hombre genérico y al ciudadano y parten de la superioridad del derecho natural sobre el positivo" y que "al deducirse de un sistema jurídico natural, previo y superior al positivo, son universales, inalienables, imprescriptibles [...]".

Manifiesta al respecto Fuentes López (2003) que "la razón es algo que comparten todos los hombres; por tal motivo, sus conclusiones pueden ser formuladas como universales y válidas para todos los tiempos" (p. 262).

El profesor colombiano González Ramírez (2015, p. 36) por su parte habla de "proposiciones fundamentales" de la "doctrina clásica del derecho natural", entre las cuales resalta aquella que sostiene que "el fundamento del derecho se adscribe por entero a la naturaleza humana, en lo que esta tiene de absoluta, permanente y universal" (p. 36).

En síntesis, para la concepción iusnaturalista racional como los derechos del hombre se descubren por medio de la razón, estos son universales, inalienables e imprescriptibles, anteriores, naturales y superiores al derecho positivo.

Como se puede observar, el criterio racionalista es adecuado para el concepto contemporáneo de derechos humanos $y$, de hecho, está vigente en él, sin embargo, niega la posibilidad de incluir en el contenido de este discurso los derechos de las minorías étnicas entendiendo que, las características de la concepción iusnaturalista racional están ideadas para responder a un comportamiento "genérico" (Peces-Barba, 1999), uniforme o universal, y no a la realidad pluricultural del mundo.

En tercer lugar, está la contribución de la concepción del derecho positivo o iuspositivismo. Para esta posición el fundamento de los derechos del hombre es la voluntad, no la razón humana, de esta manera, los iuspositivistas concentraron sus esfuerzos en construir el concepto de derecho a partir del vocablo validez (Bobbio, 2013), esto significa que es válido como derecho el producido por el hombre a través de sus instituciones políticas (Naranjo, 2006). El derecho válido, en estos términos, es el derecho positivo.

En lo concerniente al aporte de la concepción del derecho positivo al concepto de derechos humanos, Naranjo Mesa (2006) comparando el enfoque iusnaturalista con el iuspositivista indica que:

Al contrario del derecho natural, las normas del derecho positivo son elaboradas por los hombres e impuestas por ellos. Son todos aquellos mandatos expresamente aprobados y promulgados por el legislador y que están contenidos en las leyes y demás reglas jurídicas. Se trata, entonces, de disposiciones concretas, elaboradas y dictadas por el gobernante con carácter general y obligatorio. Puede decirse que el derecho positivo es la expresión jurídica del principio de la soberanía. Sus normas, producto del hombre y de sus instituciones, pueden ser modificadas, sustituidas o derogadas a voluntad suya (p. 10).

Por último, se referencia la exposición de Francisco Javier Ansuátegui Roig (2005) que admite dos situaciones que pueden coexistir en el derecho positivo: los "derechos como instituciones jurídicas" y los "ordenamientos jurídicos". Para Ansuátegui Roig (2005) el "positivismo normativo", otro nombre con el que se califica la concepción iuspositivista, "reconoce una única realidad jurídica, la que se identifica con el derecho positivo [...]. El derecho positivo es producido por el poder político institucionalizado a través de los mecanismos y procedimientos previstos [...]" (Ansuátegui, 2005, p. 311).

En este orden de ideas, explica Ansuátegui Roig (2005) que en la relación que puede coexistir entre los derechos como "instituciones jurídicas" y los "ordenamientos jurídicos", 
para la concepción del derecho positivo es "circunstancial" o "contingente", es decir que, el reconocimiento de los derechos depende de la voluntad o de los actos humanos, de ahí, continuando con Ansuátegui Roig (2005) que puede encontrarse ordenamientos jurídicos en los que se institucionalizan derechos y otros en los que no.

En resumidas cuentas, la concepción del derecho positivo afirma que son válidos los derechos del hombre si son institucionalizados en los ordenamientos o sistemas jurídicos mediante actos humanos.

Este criterio, como el del iusnaturalismo racional está en vigor en el concepto contemporáneo de derechos humanos, puesto que los derechos que contiene esta noción son todos aquellos que el hombre por medio de sus instituciones políticas reconoce como tal, a través de las normas internacionales tipo declaraciones, pactos, tratados y convenios.

Ahora bien, frente a los derechos de las minorías étnicas el criterio iuspositivista permite y ha permitido incluir derechos de esta naturaleza en el discurso contemporáneo de los derechos humanos, no obstante, no han sido fruto del "diálogo dialógico" o de la "comunicación entre culturas" que recomiendan autores como Luis Villoro (2000) y María José Fariñas Dulce (2005), debido a que simplemente han sido reconocidos por unas culturas, hacia o en favor otras.

En cuarto y último lugar, está el aporte de la concepción contemporánea del derecho. Esta tesis a diferencia de las anteriores, no formula un criterio que desvirtúa el de la teoría teológica, racional o positivista del derecho, a contrario sensu, es pragmática. Percibe los conceptos o precisiones teóricos que se adaptan a la realidad social, política, cultural y económica y los demás, simplemente terminan en el rincón de la historia, no del olvido.

Resultado de este pragmatismo, el versus teóricopráctico iusnaturalismo (sin hacer distinción entre el cristiano y el racional) contra iuspositivismo ha sido superado, conciliado y adaptado. No hay lugar a "reduccionismo" utilizando el término de Peces-Barba (1999), se ha aceptado el "dualismo" del que habla De Asís (2005) y que el fundamento de los derechos del hombre, es el hombre, entendiendo las precisiones de Bidart (1989) y del jurista argentino Gustavo Calvinho (2013) .

No obstante, surgieron otros enfoques (algunos valiéndose de las ideas principales del iusnaturalismo o del iuspositivismo) acerca de cuál debe ser el contenido de los derechos del hombre, como es el caso de la teoría de la universalidad, de la especificación y la del relativismo cultural.

En cuanto a la tesis de la universalidad de los derechos humanos vigente desde 1948 con la Declaración Universal, defiende la idea de que por el solo hecho de ser personas (Isaza, 2015) sin importar el lugar (Younes, 2014), todos los hombres tienen los mismos derechos, esto es, dice Bidart Campos que, "le son debido al hombre -a cada uno y a todos- en todas partes, o sea, en todos los Estados [...]" (1989, p. 45).

Por lo que incumbe a la corriente de la especificación o de los "derechos a la identidad" (Ferrari, 2000, p. 340), si bien es cierto que

$4 \quad$ Peces-Barba (1999) en contraste con los modelos que denomina "reduccionistas" propone un "modelo integral de los derechos humanos", esto significa una concepción que se nutre de las ideas liberales, democráticas y socialistas. De Asís (2005) a su turno, referencia una "teoría dualista" que consiste en aceptar que los derechos son materializados a través de "instrumentos jurídicos que poseen justificación moral” (p. 31). Por su parte, Bidart (1989) hablando del fundamento de los derechos humanos dice "que desde una u otra postura, con uno $\mathrm{u}$ otro fundamento, se coincida en que el hombre es sujeto de esos derechos (¿se podría decir que el hombre es su fundamento?) y el régimen político debe darles vigencia sociológica en un Estado democrático" ( $p$. 98). Finalmente, Calvinho (2013) manifiesta que "los derechos humanos le pertenecen al hombre, surgen de su dignidad como persona y tienen un carácter prepositivo, el Estado los declara y reconoce -no los otorga-. Esta pertenencia ubica al ser humano como centro, raíz y fin del ordenamiento jurídico" (p. 17). 
no se opone a la universalidad de los derechos humanos, considera que deben institucionalizarse unos derechos distintos a los universales para las personas que se encuentran "por razones culturales, sociales, físicas, económicas, administrativas [...]" (Peces-Barba, 1994, p. 626), entre otras, "en una situación de inferioridad que es necesario compensar desde los derechos humanos" (Peces-Barba, 1994, p. 626).

Esta corriente la llama Peces-Barba (1994) "universalidad de los derechos específicos" y sirve, continuando con el autor, para eliminar las circunstancias que impiden que ciertos grupos de personas (como los niños, las mujeres y las minorías étnicas) realicen en igualdad de condiciones, por la inferioridad en que se hallan, los derechos humanos universales.

En relación con la teoría del relativismo cultural al contrario de la tesis de la especificación de los derechos, esta sí se opone a la tesis de la universalidad de los derechos humanos. Para el relativismo cultural cada cultura tiene un fundamento moral de lo que es bueno y de lo que es malo y sin importar las contradicciones que se presenten entre la "variedad de sistemas morales y de justicia" (Boco y Bulanikian, 2010, p. 10), todos son válidos. Esto quiere decir, explica el filósofo mexicano Villoro (2000) que:

Toda cultura comprende creencias acerca de lo que puede considerarse como razones que justifiquen las creencias, acerca de las reglas que deben normar la conducta para alcanzar el bien común y acerca de los valores últimos que pueden otorgar sentido a la vida (pp. 175-176).

En este contexto, como cada sociedad tiene su propio fundamento de lo moralmente bueno y de lo moralmente malo, desde este enfoque, cada sociedad debe tener un sistema $\mathrm{u}$ ordenamiento jurídico en el que se institucionalicen unos derechos, por consiguiente, si los derechos humanos tienen que ser iguales y universales, desde el relativismo cultural podría afirmarse que, o esta noción no existe o estaría en ries- go su "efectividad" como lo expresa Ramin Jahanbegloo (2010).

En conclusión, para la concepción contemporánea los derechos humanos tienen una justificación moral, pero se realizan jurídicamente por la voluntad del hombre. Este fue el resultado de la pragmática pugna entre iusnaturalistas y iuspositivistas. El "debate" (Jahanbegloo, 2010) ahora es si la justificación moral debe ser universal o, por el contrario, relativa.

Para los universalistas la moral debe ser genérica, que se traduce en iguales derechos para todos los seres humanos, en oposición a los relativistas culturales $^{5}$ que consideran que la moral debe ser particular, es decir, de acuerdo con la cultura, asimismo deben ser los derechos.

Estas posiciones, hasta el momento, no permiten una conciliación (o pragmatismo) entre ambas justificaciones morales, pues como lo explica el filósofo Marcelo Dascal (citado en Bartolomei, 1996, p. 543): "la filosofía, al igual que otras disciplinas" está pasando por una "crisis de identidad", dentro de la cual está, por su supuesto, el contenido y el concepto de los derechos humanos.

No obstante, ante esta disyuntiva la tesis de la especificación de los derechos aparece como una posible solución de modo que, teniendo en cuenta las distintas realidades del mundo, principalmente la cultural, todos puedan realizar los derechos humanos, como es el caso de las minorías étnicas ${ }^{6}$.

5 Obsérvese que de cara a los derechos de las minorías étnicas, este enfoque es igual o incluso más cómodo que el de la especificación de los derechos, pero no facilita categorizarlos según las reglas del derecho internacional como derecho humano.

6 Este discurso, de todos, es el más cómodo para los derechos de las minorías étnicas en relación con el concepto de derechos humanos. No niega que tienen derechos universales e incluye los específicos o aquellos necesarios, pero diferentes (Ferrari, 2000) para que puedan ejecutar los derechos humanos universales, como el artículo 27 del Pacto Internacional de Derechos Civiles y Políticos del 16 de diciembre de 1966, el artículo 30 de la Convención sobre los Derechos del Niño del 20 de noviembre de 1989 o la Declaración 


\section{B. El concepto de minorías étnicas}

El presente acápite se ocupará de analizar el concepto de minorías puntualizando en las de naturaleza étnica con especial interés en las colombianas, de manera que se pueda comprender cómo sus derechos siendo específicos, se categorizan como derechos humanos. En este orden de ideas, Miguel Carbonell (2001) manifiesta que:

Desde un punto de vista general, existe una minoría siempre que se produzca una situación en la cual dos o más grupos humanos de diversa fuerza numérica, económica, cultural o de otro tipo, se presentan como contrapuestos dentro de una comunidad determinada. El grupo que tiene la menor fuerza numérica, económica, cultural o de otro tipo será, evidentemente, la minoría (p. 60).

Carbonell (2001) como se puede observar, propone un concepto genérico de minorías que a efectos del tema en estudio, se reduce a las minorías culturales entendiendo que en esta categoría se encuentran las étnicas.

En este sentido, importa el concepto que al respecto expone Paolo Comanducci (2000) quien clasifica las minorías en dos: by force (por fuerza) y by will (por voluntad). En la segunda categoría de minorías, Comanducci (2000) incluye las que interesan al presente escrito expresando que:

Estas minorías culturales son consideradas, y aún más se consideran, minorías by will, si su diversidad de la mayoría está determinada por una o más características a las que atribuyen valor, si exigen el respeto a su diferencia, a su especificidad, y no se limitan a pedir simple tutela contra la discriminación. Lo que las minorías by will rechazan es la homologación, la asimilación y la

sobre los Derechos de las Personas Pertenecientes a Minorías Nacionales o Étnicas, Religiosas y Lingüísticas del 18 de diciembre de 1992. inclusión forzosa en los modelos culturales de la mayoría (o de quien detente el poder) (Comanducci, 2000, pp. 194-195).

Carbonell (2001) a su turno, habla de "minorías ocasionales" (como las políticas) y de "minorías tendencialmente permanentes". Para el autor:

Las minorías tendencialmente permanentes se definen por una serie de rasgos que normalmente varían poco en el tiempo; se trata sobre todo de una noción sociológica, derivada de la presencia dentro de una comunidad de un grupo social que presenta características distintas de las que tiene la mayoría de los integrantes de esa misma comunidad. Minorías tendencialmente permanentes son aquellas que se distinguen de la mayoría por motivos religiosos, étnicos, culturales, raciales, de género, de tendencia sexual, etcétera. Esos rasgos, aunque no permanezcan inmóviles al paso del tiempo, tampoco suelen variar con demasiada frecuencia (Carbonell, 2001, pp. 61-62).

Por su parte, Daniel O'Donnell (2012) siguiendo una de las Observaciones Generales (No. 23) del Comité de Derechos Humanos (1994) asevera que "el concepto de 'minorías étnicas, religiosas o lingüísticas' se refiere a un grupo de personas que comparten una cultura, una religión y/o un idioma" (párrafo 9), es decir que O’Donnell (2012) y el Comité, se limitan a una simple reiteración que no está de más, de la definición del artículo 27 del Pacto Internacional de Derechos Civiles y Políticos del 16 de diciembre de 1966. De acuerdo con Francesco Capotorti citado en Zavaleta Villalpando et al. (2015) las minorías étnicas son:

Un grupo numéricamente inferior al resto de la población de un Estado, que se encuentra en una posición no dominante y cuyos miembros, que son nacionales del Estado, poseen características étnicas, religiosas o lingüísticas diferentes de las del resto de la población y manifiestan, aunque solo sea 
implícitamente, un sentimiento de solidaridad para preservar su cultura, sus tradiciones, su religión o su idioma (pp. 84-85).

La Organización de las Naciones Unidas (2010) explica que para identificar cuándo se está en presencia de una minoría étnica, se deben utilizar dos factores: el objetivo y el subjetivo. El factor objetivo significa que existe una etnia, una religión y un lenguaje y el factor subjetivo, que los miembros de la minoría se identifican como parte de ella.

En resumen, son minorías étnicas el grupo de personas que, dentro de una sociedad, compartiendo características como la etnia, el idioma, la religión, la cultura y la voluntad de conservar su diferencia, se distingue de un grupo de personas cuya cultura es dominante, es decir, compartida por la mayoría de los miembros de una sociedad.

En Estados "multiculturales" (Borrero, 2014) como el colombiano existe este tipo de minorías étnicas o "sujetos específicos" (Jaramillo, 2011) que, por su comportamiento que los distingue de los demás, no pueden ejercer plenamente sus derechos humanos ${ }^{7}$.

Camilo Borrero García (2014) señala que Colombia es un Estado "multicultural" porque hay cuatro grupos de "minorías étnicas diferenciadas": los pueblos indígenas, las comunidades afrocolombianas, los raizales del archipiélago de San Andrés, Providencia y Santa Catalina y el pueblo ROM o gitano.

7 De ahí, la urgencia de identificar los criterios que permiten categorizar los derechos de las minorías étnicas como derechos humanos vigentes en derecho internacional contemporáneo, de modo que, a partir de estos, se pueda llegar a conclusiones y determinar las consecuencias jurídicas de impedir que estos "sujetos específicos" (Jaramillo, 2011), por sus diferencias, no puedan ejercer sus derechos humanos.
En el país, la entidad encargada de certificar el número de habitantes y clasificarlos por sexo, etnia, edad, entre otras peculiaridades es el Departamento Administrativo Nacional de Estadística (Dane). El Dane (2007) informa que en Colombia pueden encontrarse las minorías étnicas que se citan en la tabla 1.

Tabla $1^{8}$. Minorías étnicas en Colombia

\begin{tabular}{llc}
\hline Minoría étnica & Población & \% \\
\hline Indígenas & 1392623 & 3,43 \\
\hline Afrodescendientes y raizales & 4311757 & 10,62 \\
\hline Pueblo ROM & 4858 & 0,01 \\
\hline Total & $\mathbf{5 7 0 9} \mathbf{2 3 8}$ & $\mathbf{1 4 , 0 6}$ \\
\hline
\end{tabular}

Fuente: Dane (2007).

Vale destacar que la realidad de las minorías étnicas colombianas -esto es, que necesitan para su "supervivencia" (sentencia T-461/2014)- no es igual para todas, de ahí, que Borrero (2014, p. 17) hable de "minorías étnicas diferenciadas". Las minorías o pueblo ROM necesitan de la cultura para realizar sus derechos humanos, mientras que los afrocolombianos, raizales y los pueblos indígenas, por añadidura, del territorio que tradicionalmente han ocupado debido a que él forma parte substancial de su cultura, aunque, se diferencian por el modo de poseer y adquirir la propiedad sobre dicho territorio.

\section{El surgimiento de los derechos de las minorías étnicas en el discurso de los derechos humanos}

Este aparte se ocupará de determinar cómo surgieron los derechos de las minorías étnicas como derechos humanos en el derecho internacional. De acuerdo con la Oficina del Alto

8 El Dane (2005) certifica que en el Estado colombiano hay un total de 42888592 habitantes, dentro del cual las minorías étnicas (tabla 1) equivalen a 5709 238 habitantes, es decir, el 14,06\% del $100 \%$ de los habitantes. 
Comisionado de las Naciones Unidas para los Derechos Humanos (s. f.):

Los derechos humanos son derechos inherentes a todos los seres humanos, sin distinción alguna de nacionalidad, lugar de residencia, sexo, origen nacional o étnico, color, religión, lengua, o cualquier otra condición. Todos tenemos los mismos derechos humanos, sin discriminación alguna. Estos derechos son interrelacionados, interdependientes e indivisibles.

Si bien es cierto que los derechos humanos están interrelacionados y que son interdependientes e indivisibles, han sido clasificados de diversas maneras por la doctrina. Todas estas ordenaciones siguen indiscutiblemente el criterio "historiográfico" (sentencia T-008/1992) que describe cómo surgieron los derechos humanos en su dimensión individual, social y colectiva, al mismo tiempo, identifica su objetivo principal y los organiza cronológicamente.

Armando Hernández Cruz (2010) y la Corte Constitucional colombiana (sentencia T-008/1992) exponen la tesis de la clasificación de los derechos en generaciones propuesta por el jurista checo Karel Vašák, según explica Contreras Nieto (2003), mientras que Ferrari (2000) presenta una que es más precisa, denominada evolucionista por Thomas H. Marshall.

En este sentido, se puede hablar de derechos humanos de primera, segunda y tercera generación (sentencia T-197/2014) o, de derechos civiles, derechos políticos, derechos sociales y derechos a la identidad (Ferrari, 2000). Los primeros corresponden a la tesis de las generaciones de los derechos, los segundos, a la teoría evolucionista que se refiere a cada clase de derecho por su nombre. No obstante, observando bien ambas ordenaciones no presentan mayores contradicciones, más bien coinciden en el contenido y la manera como nacieron las distintas categorías de derechos humanos. Teniendo en cuenta la tesis de las generaciones y la evolucionista, los derechos humanos aparecieron en el siguiente orden:

1. De primera generación o derechos civiles $y$ políticos. Esta generación contiene los derechos que garantizan la libertad personal e ideológica del hombre. Los derechos de primera generación son el resultado del movimiento del constitucionalismo liberal (Naranjo, 2006) y, hoy en día, su contenido puede encontrarse principalmente en la Declaración Universal de los Derechos Humanos de 1948.

2. De segunda generación o derechos sociales. Estos derechos con los de primera generación, forman parte del contenido de la Declaración Universal de los Derechos Humanos de 1948, pero se distinguen de los derechos civiles y políticos en que protegen al hombre en su dimensión social (Naranjo, 2006).

3. De tercera generación o derechos a la identidad. Esta generación de derechos protege a las colectividades humanas (Naranjo, 2006) que, por el estado de "inferioridad" en que se encuentran, necesitan además de los derechos individuales, civiles y políticos, de derechos específicos (Peces-Barba, 1994) para poder realizarse humanamente.

Como se puede apreciar, es en los derechos de tercera generación (o derechos a la identidad) que surgen los derechos de las colectividades como las que se estudian en este documento: las minorías étnicas.

Estos derechos, según sea el grupo de personas que protegen reciben una denominación, así, puede hablarse de un género: "derechos a la identidad" (Ferrari, 2000, p. 340) por cuanto identifican a un grupo o a unos "sujetos específicos" (Jaramillo, 2011) que reúnen las mismas características, que en materia de minorías étnicas recibe el nombre de derechos culturales (De Yturbe, 1998). 
El reconocimiento de los derechos de las minorías étnicas en el derecho internacional de los derechos humanos, inicia y se incluye en los derechos de tercera generación por medio del Pacto Internacional de Derechos Civiles y Políticos del 16 de diciembre de 1966, en el artículo $27^{9}$ que dispone:

En los Estados en que existan minorías étnicas, religiosas o lingüísticas, no se negará a las personas que pertenezcan a dichas minorías el derecho que les corresponde, en común con los demás miembros de su grupo, a tener su propia vida cultural, a profesar y practicar su propia religión y a emplear su propio idioma.

Hoy en día, existe además del artículo 27 en mención un cuerpo de convenios, declaraciones y resoluciones de los órganos internacionales que se refieren a los derechos de las minorías étnicas como derechos humanos. En el siguiente acápite, se señala cuáles son.

$9 \quad$ Si bien el Pacto Internacional de Derechos Civiles y Políticos consagra los derechos humanos de carácter individual que corresponden a la primera generación de derechos y, en él está incluido el artículo 27 en mención, su naturaleza también es colectiva. En relación con la doble naturaleza del artículo 27 ha dicho el Comité de Derechos Humanos (1994):

"Aunque los derechos amparados por el artículo 27 sean derechos individuales, dichos derechos dependen a su vez de la capacidad del grupo minoritario para conservar su cultura, su idioma o su religión. En consecuencia, puede ser también necesario que los Estados adopten medidas positivas para proteger la identidad de una minoría y los derechos de sus miembros a gozar de su cultura y su idioma perfeccionándolos y a practicar su religión, en común con los otros miembros del grupo. En este sentido, se debe observar que dichas medidas positivas deben respetar las disposiciones del párrafo 1 del artículo 2 y el artículo 26 del Pacto, tanto en lo que se refiere al tratamiento de las distintas minorías como en lo relativo al tratamiento entre las personas pertenecientes a ellas y el resto de la población. Sin embargo, en la medida en que estén destinadas a corregir una situación que impide o dificulta el goce de los derechos garantizados por el artículo 27, dichas medidas pueden constituir una diferenciación legítima con arreglo al Pacto, con tal de que estén basadas en criterios razonables y objetivos" (párrafo 6.2).

\section{Discusión de una propuesta: el derecho internacional de los derechos humanos de las minorías étnicas}

El 10 de diciembre de 1948 fue adoptada por la comunidad internacional (Cerna, 1995) la Declaración Universal de los Derechos Humanos, un documento normativo internacional de un preámbulo y treinta artículos que institucionaliza los derechos individuales y sociales necesarios para que las personas puedan realizarse dignamente. Sin embargo, su pretensión o "vocación universalista" (sentencia T-008/1992) resultó ser ineficaz a todas luces, incluso hasta nuestros días. ¿Por qué?

El desconocimiento de la realidad del hombre tarde o temprano obliga a las instituciones jurídicas o cambiarse o a modificarse. El error de la política internacional en aquel entonces fue ignorar que el articulado de los derechos humanos debía adaptarse a la realidad de las culturas de nuestro mundo y no simplemente a una o unas culturas en particular.

Por esta circunstancia, la política internacional o la cultura dominante para mayor precisión, debió remediar su error y así como ha sucedido con el liberalismo de frente a las críticas del socialismo (Naranjo, 2006), aunque no cambió ni mucho menos modificó su normatividad y sus instituciones, estableció otras fruto de comparar el concepto de lo que institucionalizaron como derechos humanos, con las distintas realidades culturales del ser humano, las cuales pueden hallarse en los derechos de tercera generación (Naranjo, 2006).

Es así como nace una especie de figura jurídica que partiendo de la opinión consultiva OC16/1999 de la Corte Interamericana de Derechos Humanos puede denominarse como el derecho internacional de los derechos humanos de las minorías étnicas. ¿Qué es? 
Puede definirse como el conjunto de "tratados, convenios, resoluciones y declaraciones" o corpus iuris (opinión consultiva OC-16/1999) que permite contextualizar o "conjugar" (Clavero, 2014) la realidad de las minorías étnicas, con el concepto que se admite de derechos humanos.

Esta contextualización o "conjugación” (Clavero, 2014) es posible como atrás se señaló con la tesis de la especificación de los derechos. Hoy por hoy, el derecho internacional de los derechos humanos de las minorías étnicas está integrado de la siguiente manera:

- El artículo 27 del Pacto Internacional de Derechos Civiles y Políticos del 16 de diciembre de 1966.

- El Convenio 169 sobre Pueblos Indígenas y Tribales del 27 de junio de 1989.

- El artículo 30 de la Convención sobre los Derechos del Niño del 20 de noviembre de 1989.

- La Declaración sobre los Derechos de las Personas Pertenecientes a Minorías Nacionales o Étnicas, Religiosas y Lingüísticas del 18 de diciembre de 1992.

- La Declaración de las Naciones Unidas sobre los Derechos de los Pueblos Indígenas del 13 de septiembre de 2007.

- Las resoluciones de los órganos internacionales que interpretan las normas sobre los derechos humanos de las minorías étnicas.

Hoy en día, aunque se conocen otras normas internacionales que se refieren a las minorías étnicas las que contienen sus derechos como derechos humanos, son las que se acaban de anotar.

\section{Conclusiones}

En principio, el concepto de derechos humanos aunque reconoció derechos a todos los seres humanos, no lo hizo en todos los contextos en que los mismos pueden realizarse. El resultado de universalizar derechos, pero no contextos fue excluir a grupos específicos de personas que tenían derechos, que no podían ejercitar. Por consiguiente, la idea de derechos humanos evolucionó institucionalizando los derechos necesarios para que todas las personas puedan ejecutar los derechos humanos, como es el caso de las minorías étnicas.

En el presente, puede decirse que los derechos de las minorías étnicas son derechos humanos, puesto que:

1. Las normas internacionales de derechos humanos institucionalizadas desde 1948, cuyo principal desarrollo inicia en 1966 con los pactos internacionales, demuestran que sean derechos individuales, sociales o colectivos, su inequívoca fundamentación es el hombre sin distinción alguna.

2. Las minorías étnicas ejercen los mismos derechos individuales, sociales y colectivos que los demás seres humanos, pero en contexto cultural totalmente diferente.

3. Los derechos reconocidos como derechos humanos son todos aquellos que los hombres legitiman como tal, dentro de los cuales están los derechos de las minorías étnicas cuyo desarrollo, cada día es más extenso.

4. La finalidad de las normas internacionales de los derechos humanos es que todas las personas se realicen humana y dignamente, en este sentido, cualquier derecho que permite este desarrollo debe calificarse como derecho humano, como los derechos de las minorías étnicas institucionalizados en el derecho internacional de los derechos humanos.

5. Desconocer que los derechos de las minorías étnicas son derechos humanos, afectaría la protección tanto de sus derechos específicos como de sus derechos universales debido a que sin los unos, no se pueden realizar los otros. 


\section{Referencias}

Ansuátegui, F. J. (2005). Ordenamiento jurídico. En: J. J. Tamayo (ed.). 10 palabras claves sobre los derechos humanos (pp. 15-54). Navarra: Verbo Divino.

Atienza, M. (2011). El derecho como argumentación. En: M. Carbonell, J. J. Orozco Henríquez \& R. Vázquez (eds.). Jurisdicción y argumentación en el Estado constitucional de derecho (pp. 1-86). Ciudad de México: Universidad Nacional Autónoma de México.

Bartolomei, M. L. (1996). Universalismo y diversidad cultural en América Latina. En: A. A. Cançado Trindade, C. Moyer \& C. Zeledón (eds.). Estudios básicos de derechos humanos VI (pp. 520-539). San José: Mundo Gráfico.

Bidart, G. J. (1989). Teoría general de los derechos humanos. Ciudad de México: Universidad Nacional Autónoma de México.

Bobbio, N. (2013). Teoría general del derecho. Bogotá: Temis.

Boco, R. \& Bulanikian, G. (2010). Derechos humanos: universalismo us. Relativismo cultural. Alteridades, 20(40). Disponible en: http://www.scielo.org. $\mathrm{mx} /$ scielo.php?script=sci_arttext\&pid $=$ S0188-70172010000200002

Borrero, C. (2014). Derechos multiculturales (étnicos) en Colombia. Una dogmática ambivalente. Bogotá: Universidad Nacional de Colombia.

Calvinho, G. (2013). La procedimentalización posmoderna. Revista del Instituto Colombiano de Derecho Procesal, 39, pp. 11-31.

Carbonell, M. (2001). Minorías etno-culturales y derechos colectivos: premisas conceptuales. En: D. Valdés \& R. Gutiérrez Rivas (eds.). Derechos humanos, memoria del IV Congreso Nacional de Derecho
Constitucional (pp. 55-70). Ciudad de México: Universidad Nacional Autónoma de México.

Cerna, C. M. (1995). La universalidad de los derechos humanos y la diversidad cultural: la realización de los derechos humanos en diferentes contextos socioculturales. En: A. A. Cançado Trindade \& L. Gonzales Volio (eds.). Estudios básicos de derechos humanos II (pp. 377-396). San José: García Hnos.

Clavero, B. (2014). El derecho global. Por una historia verosímil de los derechos humanos. Madrid: Trotta.

Comanducci, P. (2000). Derechos humanos y minorías: un acercamiento analítico neoilustrado. En: M. Carbonell, J. A. Cruz Parcero \& R. Vázquez (eds.). Derechos sociales y derechos de las minorías (pp. 185-206). Ciudad de México: Universidad Nacional Autónoma de México.

Comité de Derechos Humanos. (1994). Observación general 23 al artículo 27 del Pacto Internacional de Derechos Civiles y Políticos. Disponible en: http://www. hchr.org.co/documentoseinformes/documentos/html/informes/onu/cdedh/ Observacion\%20Gral.\%2023\%20Art\%20 27\%20PDCP.html

Constitución Política de Colombia. (1991). Artículo 93.

Contreras, M. A. (2003). 10 temas de derechos humanos. Ciudad de México: Universidad Nacional Autónoma de México.

Convenio 169 sobre Pueblos Indígenas y Tribales. (1989). Preámbulo.

Convención Americana sobre Derechos Humanos. (1969). Preámbulo.

Convención sobre los Derechos del Niño. (1989). Artículo 30.

Corte Constitucional de Colombia. (1992). Sentencia T-008. M. P. Simón Rodríguez Rodríguez y Jaime Sanín Greiffenstein. 
Corte Constitucional de Colombia. (2014). Sentencia T-461. M. P. Gabriel Eduardo Mendoza Martelo.

Corte Constitucional de Colombia. (2014). Sentencia T-197. M. P. Alberto Rojas Ríos.

Corte Interamericana de Derechos Humanos. (1999). Opinión consultiva OC-16/99 de 1 de octubre de 1999. Disponible en: http://www.corteidh.or.cr/docs/opiniones/seriea_16_esp.pdf

De Asís, R. (2005). Concepto y fundamento de los derechos humanos. En: J. J. Tamayo (ed.). 10 palabras claves sobre los derechos humanos (pp. 15-54). Navarra: Verbo Divino.

De Yturbe, C. (1998). Multiculturalismo y derechos. Ciudad de México: Instituto Federal Electoral.

Declaración de las Naciones Unidas sobre los Derechos de los Pueblos Indígenas. (2007). Preámbulo.

Declaración sobre los Derechos de las Personas Pertenecientes a Minorías Nacionales o Étnicas, Religiosas y Lingüísticas. (1992). Preámbulo.

Declaración Universal de los Derechos Humanos. (1948). Preámbulo.

Departamento Administrativo Nacional de Estadística. (2005). Censo general 2005. Nivel nacional. Disponible en: http:// www.dane.gov.co/censo/files/libroCenso2005nacional.pdf

Departamento Administrativo Nacional de Estadística. (2007). Colombia una nación multicultural. Su diversidad étnica. Disponible en: http://www.dane.gov.co/files/ censo2005/etnia/sys/colombia_nacion. pdf

Fariñas, M. J. (2005). Universalidad e interculturalidad. En: J. J. Tamayo (ed.). 10 palabras claves sobre los derechos humanos (pp. 195-231). Navarra: Verbo Divino.
Ferrari, V. (2000). Acción jurídica y sistema normativo. Introducción a la sociología del derecho. Madrid: Dykinson.

Fuentes, C. (2003). El racionalismo jurídico. Ciudad de México: Universidad Nacional Autónoma de México.

Giraldo, J., Giraldo, L. M. \& Giraldo, L. A. (2002). Metodología y técnica de la investigación sociojurídica. Bogotá: Librería Ediciones del Profesional.

González, A. (2015). Introducción al derecho. Bogotá: Librería Ediciones del Profesional.

Hernández, A. (2010). Los derechos económicos, sociales y culturales y su justiciabilidad en el derecho mexicano. Ciudad de México: Universidad Nacional Autónoma de México.

Isaza, H. E. (2015). Derechos humanos y sistema interamericano. En: E. A. Velandia (ed.). Derecho procesal constitucional (pp. 533-550). Bogotá: Legis.

Jahanbegloo, R. (2010). Derechos humanos y relativismo cultural. Disponible en: http:// www.amnistiacatalunya.org/edu/2/dh/ dh-der-r.jahanbegloo.html

Jaramillo, R. D. (2011). Relativismo cultural vs. derechos humanos: ¿confrontación o tolerancia? Disponible en: https:// aprendeenlinea.udea.edu.co/revistas/ index.php/almamater/article/viewFile/8582/7937

López, D. E. (2006). El derecho de los jueces. Bogotá: Legis.

Monroy, M. G. (2013). La interpretación constitucional. Bogotá: Librería Ediciones del Profesional.

Monroy, M. G. (2015). Introducción al derecho. Bogotá: Temis.

Naranjo, V. (2006). Derecho constitucional e instituciones políticas. Bogotá: Temis.

Nikken, P. (1994). El concepto de los derechos humanos. En: R. Cerdas Cruz \& R. Nieto 
Loaiza (eds.). Estudios básicos de derechos humanos I (pp. 15-37). San José: Prometeo.

O’Donnell, D. (2012). Derecho internacional de los derechos humanos, normatividad, jurisprudencia y doctrina de los sistemas universal e interamericano. Ciudad de México: Oficina en México del Alto Comisionado de las Naciones Unidas para los Derechos Humanos.

Oficina del Alto Comisionado de las Naciones Unidas para los Derechos Humanos. (s. f.). ¿Qué son los derechos humanos? Disponible en: http://www.ohchr.org/SP/ Issues/Pages/WhatareHumanRights.aspx

Organización de las Naciones Unidas. (2010). Derechos de las minorías: normas internacionales y orientaciones para su aplicación. Disponible en: http://www. ohchr.org/Documents/Publications/MinorityRights_sp.pdf

Ottone, E. (1996). Desarrollo y cultura. Una visión crítica de la modernidad en América Latina y el Caribe. En: A. A. Cançado Trindade, C. Moyer \& C. Zeledón (eds.). Estudios básicos de derechos humanos VI (pp. 520-539). San José: Mundo Gráfico.

Pacto Internacional de Derechos Civiles y Políticos. (1966). Preámbulo y artículo 27.
Pacto Internacional de Derechos Económicos, Sociales y Culturales. (1966). Preámbulo.

Peces-Barba, G. (1994). La universalidad de los derechos humanos. Doxa, I(15-16), pp. 613-633. Disponible en: http://www. corteidh.or.cr/tablas/r28867.pdf

Peces-Barba, G. (1999). Curso de derechos fundamentales. Teoría general. Madrid: Universidad Carlos III de Madrid, Boletín Oficial del Estado.

Villoro, L. (2000). Sobre el relativismo cultural y el universalismo ético. En torno a las ideas de Ernesto Garzón Valdez. En: M. Carbonell, J. A. Cruz Parcero \& R. Vázquez (eds.). Derechos sociales y derechos de las minorías (pp. 185-206). Ciudad de México: Universidad Nacional Autónoma de México.

Younes, D. (2014). Derecho constitucional colombiano. Bogotá: Legis.

Zavaleta, I. Y., Río, S., Antillón, S. I., Pérez, L., Ramírez, M. E., Ojeda, O. B., Ramírez, A. D., Rosas, L. F., Mendoza, F. \& Torres, A. (2015). Derechos colectivos y reconocimiento constitucional de las poblaciones afromexicanas. Ciudad de México: Consejo Nacional para Prevenir la Discriminación. 